\title{
Research on Cooperative Interactive Teaching Model in College English Based on Multimedia Network
}

\author{
Yingxin Cheng
}

Teaching and Research Institute of Foreign Languages, Bohai University, Jinzhou, 121013, China

506521127@qq.com

Keywords: multimedia network; college English; cooperative learning; interactive teaching

\begin{abstract}
In view of the present situations that the traditional college English teaching is mainly based on teachers' teaching, students are in a passive learning state, the classroom atmosphere is boring and students' positive initiative can't play, this paper researches collaboration interactive teaching mode based on multimedia network technology. Based on the advantages of multimedia network English teaching mode, the multimedia network English teaching platform is constructed, college English collaborative interactive teaching strategies are put forward. Specific strategies include: find the best combining point of multimedia and teaching materials, exert students' subjectivity, combine with conventional teaching methods, create appropriate interactive environment and change teachers' role and so on. The research results of this paper have important significance in promoting college English teaching reform and improving the quality of English teaching and so on.
\end{abstract}

\section{Introduction}

The teaching goal of college English is to cultivate students' English comprehensive application abilities, especially listening and speaking abilities, which make them in the future study, work and social interactions can use English to communicate effectively, and enhance their ability of autonomous learning, improve their comprehensive cultural quality to meet the need of social development in our country and international communication. Due to the influence of exam-oriented education, the traditional English teaching in quite a long period of time is dominated by teachers' teaching in the class, the class is limited to dialogue, discussion, explanation, most rely on a piece of chalk, a book and a blackboard of teachers, students are in a passive learning state, single teaching equipment, monotonous teaching forms, depressing classroom atmosphere, which is not conducive to students to learn actively [1]. This kind of teaching mode makes English which is a very strong practical course become common knowledge classes, while students cultivated in this model, their language knowledge are very far from the ability and requirements of practical use of English. Therefore, it is necessary to change the traditional teaching mode. Modern foreign language teaching is developing towards the direction of the multimedia, integration, network, if in the English classroom teaching, reasonably and effectively applying the multimedia network technology into the teaching practice, which has a positive role for mobilizing students' audio-visual feeling, stimulating students' interests in learning, cultivating students' ability of independent analysis, thinking, cooperation and communication.

\section{Theoretical Principle}

\section{(1) Situated Cognition Theory}

Situated cognition theory is another important research direction at the emergence of constructivism, which is followed by the behaviorism learning theory of "stimulus - response" and the learning theory of "information processing" of cognitive psychology. The basic idea is that knowledge is situational, knowledge is part of the activities, background and cultural products. Knowledge is constantly used and developed in activities, rich situations and cultures.

The teaching view of the situated cognition theory holds that the situational teaching aims at cultivating students' ability to solve practical problems, realizing the unity of knowledge and 
practice, the harmonious development of physical and mental, students are required to be placed in a specific problem situation. With the help of students' life experience and activities in the daily life situation closely linked with the real world to carry on. Teachers in the classroom show the similar exploration process that experts solve problems to provide the prototype and framework solves the problem, build the corresponding situation, which promotes the communication, cooperation and exploration between learning community members. Study effect evaluation is consistent with the learning process, the process itself that students solve specific problems in the study reflects the learning effect [2].

Situated cognition theory emphasizes that the design of learning takes learners as the main body, the arrangements of contents and activities should connect with the concrete practice of the human society, the best in the real situation, through the manner similar to human practice to organize teachings, at the same time, integrate the knowledge and acquisition together with learners' developments and identity constructions. Anyway, the view of situated cognition theory affects the teaching philosophy of various aspects of teaching system design and learning environment development, which provides a theoretical basis for new areas of the education technology of the information technology and curriculum integration, computer support collaborative learning, virtual learning community construction and so on.

\section{(2) Constructivism Theory}

The constructivism theory is the educational psychology theory which appears after the behaviorism and cognitivism, which better reveals the cognitive law of human learning process, emphasizes "Learner centered theory", the focus from the traditional teaching emphasizes "teaching" to "learning", knowledge is not a simple information input, storage and extraction process, but the process that learners based on the existing cognitive and experience self-construct new knowledge, the process that collides new and old information and stimulates growth with others' cooperation. Because of individual cognitive structure and level differences, understanding the angle and cut surface of things is also different, but through mutual cooperation can make the understanding more comprehensive.

The basic viewpoints of constructivism theory are as follows: about "knowledge", it thinks that knowledge is self-constructed by learners inner, influenced by social culture, achieved by the interaction of the individual's old cognition and new information; about "learning", knowledge learning is not taught by teachers, but learners under certain situations, inspired by others, leveraging learning materials for self-construction; about "teachers", requires teachers transfer the teaching method from transmitting knowledge to learners to guiding learners to self-construct knowledge, and provide learners required guidance and help in the process of construction, form a cooperative relationship with learners; about "students", students are not absolutely ignorant before learning, but think of new knowledge with existing experience. Students previous learning and in the contact with the social situation, which has formed their own unique cognitive structure and cognitive methods, they have their own opinions for any knowledge.

In the teaching process, students should be taken as the main body, respecting students' existing experience, making use of students' existing cognition, which makes students better absorb knowledge, and takes them into their cognitive structure. At the same time, students will play the main role, actively use the data to construct the significance of knowledge, and learn to integrate new and old knowledge, pay attention to the role of independent and collaborative communication.

\section{Advantages on Multimedia Network English Teaching Mode}

Modern foreign language teaching is developing towards the direction of the multimedia, integration, networking, if the multimedia network technology can be applied in the teaching practice reasonably and effectively in the English class, which has positive effects for mobilizing audio-visual feeling, stimulating interest in learning, cultivating the ability of independent analysis, thinking and cooperation and communication. Advantages are as follows:

First, conductive to create a good English communication environment. Quality and efficient classroom communicative activities can stimulate students' learning motivation, let students have 
the opportunity to practice the overall expression ability, which is advantageous to students to learn languages naturally. To do this, teachers must create a good social environment, leaving the scene is not realistic. Only sticking into the language environment of life can make students easy to accept and be interested in. Making use of multimedia network teaching can more conveniently show perceptual materials and reproduce the things students have never seen through images on the screen, which create a fully illustrated, colorful, vivid, immersive teaching environment.

Second, help to expand the amount of English classroom practice. The use of the specific practice that multimedia network technology writes, the practice effect is very good, especially help to exercises drill, a large number and intuitive. This is that a traditional practice method cannot achieve. Change from passive to active, Change from abstract to concrete, through entertaining exercises, easily consolidating the learned knowledge, inspiring students' learning interests from the deep in the heart, really achieve the goal that "reduce the burden and improve the quality". Various forms of choice, fill-in and true-false questions are added in practice, using the software to determine whether students' answer is correct or not, according to the practice situation, automatically adjust the difficulty of the examination questions.

Third, conducive to the realization of the collaborative interaction. Through discussion, communication and collaboration, revise, supplement and discuss different ideas, deepening the understanding of the problem, promoting senior cognitive abilities by communications and cooperation, cultivating the spirit of collaboration. realization of the collaborative interaction between teachers and students, with the aid of the multimedia teaching system and local area network communication system, realizing ideas communication and information feedback; Implementing the interactivity between students and teaching contents and teaching medias, students choose the teaching content with appropriate difficulty according to their own situation to take actively to complete study tasks, which realizes the interaction between learners and teaching contents and teaching medias.

Forth, beneficial to improve the students' ability of listening, speaking, reading and writing. Using multimedia technology to create English communication environment, making use of modern teaching means such as TV, audio and video to act the content such as language, image and sound on students' variety of senses at the same time, which lets students use the left and right brain and results in the "immersive" feeling, fully mobilizes students' learning interests and enthusiasm. The English simulation communication training is carried out under teachers' guidance, the ability of using English directly gets exercise, more effective in improving English communication skills, the comprehensive ability of listening, speaking and writing has been continuously improved.

\section{Constitution on Multimedia Network English Teaching Platform}

The Multimedia network teaching platform is based on the needs of modern education teachings, which is a comprehensive teaching system combining multimedia computer, projection, audio, video and other modern teaching media together. It can make teachers conveniently and neatly apply multimedia to implement multimedia combination teaching, and the teaching process more in line with the laws of cognition, comprehension and memory of the students to improve the teaching effect and efficiency. The multimedia network English teaching platform consists of the hardware system and software system.

(1) Hardware system. Using the output device such as a projector or TV set to display the signal of computers, video display platforms and other video equipment, and making use of the central control system to make simple switch of information, provide the following basic functions: connecting campus network, CERNET and Internet makes teachers can easily call the rich network resources, which realizes the network online teaching; connecting the closed-circuit television system gives full play to the role of TV media in teachings; demonstrates all kinds of multimedia teaching courseware, carries out the computer assisted teaching; plays video, VCD and DVD video teaching programs; displays material objects, models, pictures and texts data; can display computer information and all kinds of video signals with high resolution and large screen projectors; play all kinds of sound signals with the hi-fi system. The hardware system structure is shown in Fig. 1. 


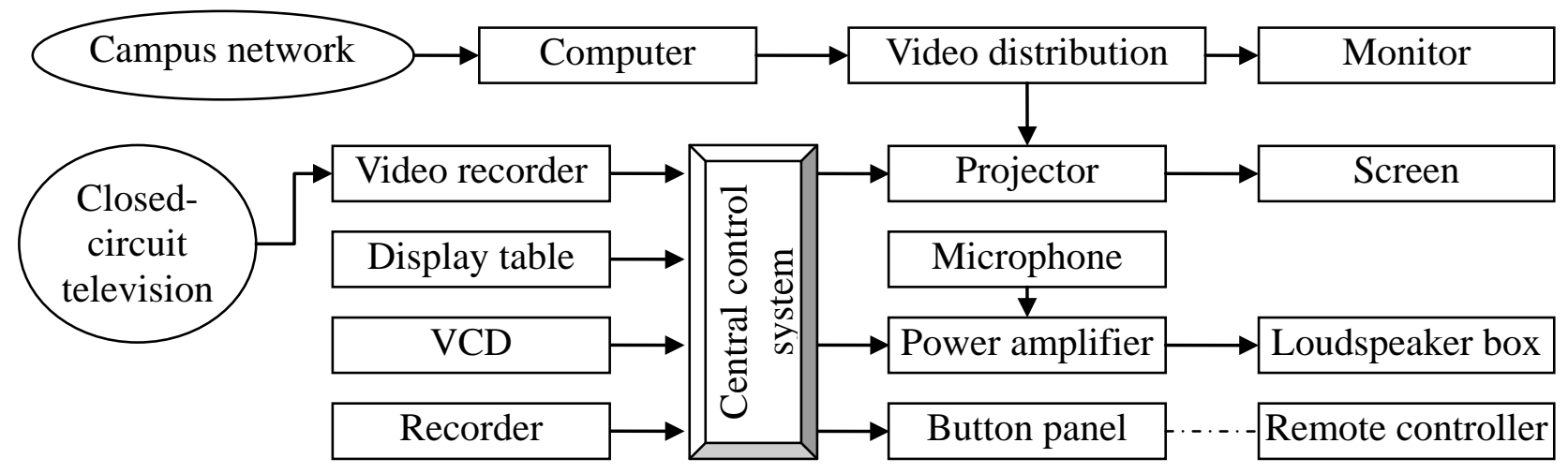

Fig. 1. Hardware system structure on multimedia network English teaching platform

(2) Software system. The multimedia teaching software system is a computer teaching program that designed according to the teaching goal, performs specific teaching contents, reflects a certain teaching strategy, the teaching media which can be used to store, transfer and process teaching information, can let students to carry on the interactive operation, and makes evaluations for students' learning. Multimedia teaching software has the following characteristics: graphic audio-visual and texts stimulate students' interest in learning; a friendly interactive environment mobilizes students' active participations; rich information resources expand students' knowledge; hypertext structure information provides a variety of learning path. The software system structure is shown in Fig. 2.

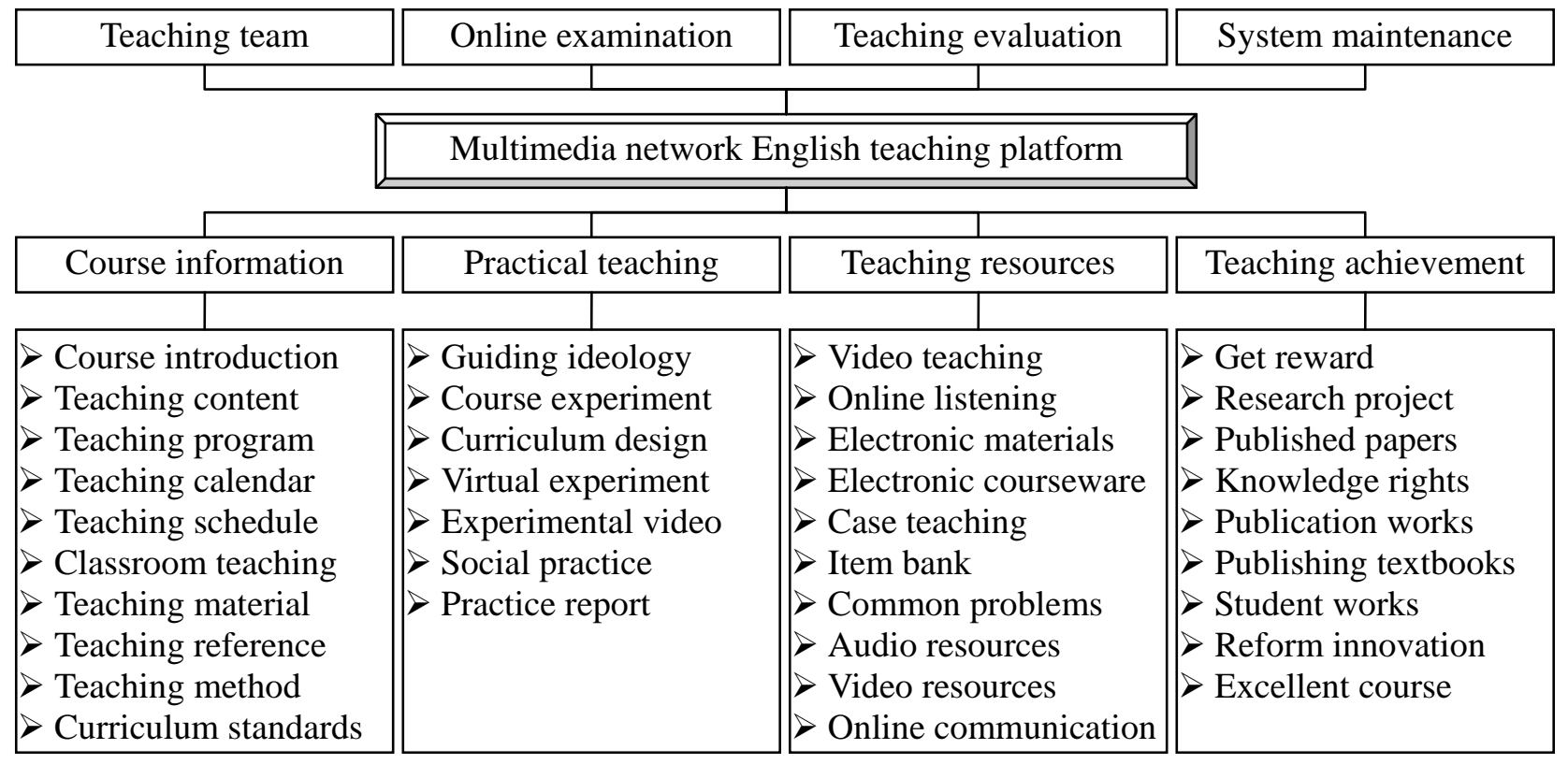

Fig. 2. Software system structure on multimedia network English teaching platform

\section{Strategy on College English Cooperative Interactive Teaching}

Aiming at the characteristics of multimedia network teaching and college English teaching, cooperative interaction teaching strategies are put forward as follows [3-8]:

(1) Study teaching materials, find out the best combining point of multimedia and teaching materials. Not all teaching links are suitable for the multimedia, the multimedia should adapt to the teaching content, both should be organically integrated. Teachers should make sure that the emphasis and difficulties of the materials, think about that how to highlight the key points and difficulty through courseware, select the teaching mode and material which is helpful for students to understand and grasp, follow students' thought laws, correctly handle the relationship between modern teaching means and teaching purposes, determine the status that multimedia services the 
teaching when prepare a lesson. Language teaching is inseparable from the situation, teachers can make use of the advantages of a variety of information of the multimedia text, images, video, sound, animation and other information which is a whole to create the necessary communication scene, provide students with a lot of opportunities for language practice, fully reflect the practicality of the English classroom teaching.

(2) Pay attention to "student-oriented", exert students' subjectivity. The idea of "student oriented" is more and more popular in the educational circles. In the process of teaching, taking students as the center, fully exerting students' subjectivity, which has become the teaching method popular with teachers. Therefore, when making use of multimedia network technology to do auxiliary teaching, should fully reflect students' initiative and creativity, and create more thinking space for students. When teachers use multimedia network auxiliary teaching system, good at guiding students to think, discuss and answer questions through the multimedia teaching system, rather than restrict students' thinking, passively following teachers' thinking.

(3) Avoid that pay too much attention to the multimedia and interactive and ignore conventional teaching methods. Although multimedia teaching has many advantages, but cannot blindly pursue the modern teaching form in the process of teaching, only pay attention to the surface, completely abandon conventional teaching tools. Teachers should according to the course content, select the most appropriate media and means, reasonably combine multimedia and traditional media. Take blackboard writing as an example, some English teachers take a computer screen as the blackboard, it is not reasonable, because the screen only displays in a short time teaching contents, cannot display the contents and difficult points of the whole lesson in a screen, which affects students' grasp for the whole content. Teachers can change the blackboard content at any time according to students' mastery degree. Combining with a variety of teaching means conducive to improve classroom efficiency in the teaching activities can learn from each other, maximize the effectiveness of teaching.

(4) Create an appropriate interactive environment. Create a classroom environment conducive to learning. Teachers in the English classroom interactive teaching strengthen the emotional cultivation and communication between teachers and students. Form a relaxed and pleasant atmosphere in the classroom, students are encouraged to actively participate in the interactive teaching, so that English classroom interactive teaching can have vitality. To create a classroom environment conducive to English interactive teaching, the import stage in the classroom teaching should be interesting and novelty, more use of multimedia and other equipment to increase students' sense of freshness. When teachers design the subject and scope discussed in the classroom teaching, pay attention to lively and varied, especially choose the topic everyone is interested in, pleasant English interactive atmosphere.

(5) Change the role of teachers. Change the subject status of teachers in the classroom, change the wrong view that teachers are the managers and controllers of teaching activities, and students can only accept and execute. English classroom interactive teaching carries out smoothly, first of all, teachers transform the role status in the classroom. In the process of English classroom teaching, students' subject status is fully displayed, the enthusiasm and initiative of students' participation are mobilized. To maintain the equal status of the relationship between teachers and students, teachers should respect students, treat students equally, students also love their teachers, respect teachers, and cooperate with teachers English classroom interactive teaching activities in the action. Teachers should guide students to participate in the interaction with democracy and equal attitude, so as to help to the smooth progress of classroom interaction. Only teachers treat students equally can make the teaching process become the process of positive emotional communication between teachers and students, promote students' initiative, stimulate students' thirst for knowledge, muster the self-confidence of learning.

\section{Conclusion}

With the wide application of computer technology and network technology, multimedia network education as a new education method provides a brand-new education idea, the abundant education 
resources and necessary software and hardware environment support for China's education reform. Compared with the traditional education, multimedia network education has improved the technology content, promoted the teacher role transformation, and enhanced the students' subject status, which is conducive to the cultivation of the students' ability and quality. The relationship that multimedia network education on the reform of public English teaching is particularly close, with modern information technology, especially the new teaching mode supported by network technology creates virtual teaching environment, provides a lot of information resources, which makes the teaching is no longer restricted by time and space, creates the conditions for students individualized learning and autonomous learning. This paper researches that combining multimedia network technology and college English collaborative interaction creates a new teaching mode, strengthening the interaction between teachers and students, encouraging students to actively participate, which is of great significance for promoting college English teaching reform and improving the quality of English teaching and so on.

\section{Acknowledgement}

This work is supported by The seventh batch of "China's foreign language education fund" of China foreign language education and research center of Beijing foreign studies university of humanities and social sciences key research base ministry of education (ZGWYJYJJ2014A28): Research on Cooperative Interactive Teaching Model in College English Based on Multimedia Network.

\section{References}

[1] X. J. Yuan, "Application of Interactive Teaching in College English Teaching," Journal of Changchun Education Institute, vol. 31, no. 6, pp. 96-97, 2015.

[2] Now and Then' Blog, "Situated cognition theory," http://blog.sina.com.cn/s/blog_6d3a3c260101k315.html, 2016-1-3.

[3] X. L. Ye, P. Luo, "A Study on Multi-dimensional Interaction Teaching Model of English Listening and Speaking," Journal of Chengdu Normal University, vol. 31, no. 2, pp. 42-46, 2015.

[4] Y. T. Liu, "On the strategies of interactive teaching in English classroom," Journal of Teaching and Management, vol. 27, no. 36, pp. 113-114, 2010.

[5] J. H. Zhang, H. W. Sun, "Application of Interactive Teaching in College English Classroom Teaching," Journal of Jilin Radio and TV University, vol. 23, no. 8, pp. 127-12, 2010.

[6] Q. Q. Zhao, "A Research on How Constructivism Theory Instructs the Teaching of English Reading in Senior High School," Master's degree of Shanghai Normal University, 2012.

[7] G. Han, "Online collaborative learning system based on Multimedia," Master's degree of Xidian University, 2012.

[8] H. Y. Deng, "Interactive mode to improve the teaching effect of English," China Higher Education, vol. 50, no. 23, pp. 42-43, 2014. 